\title{
Prime oxygen concentration has no effect on placental vascular resistance for fetal cardiac bypass
}

\author{
Charles R. Cole, MD, ${ }^{a}$ R. Scott Baker, BS, ${ }^{a}$ Danielle Herbert, BS, ${ }^{a}$ and Pirooz Eghtesady, MD, PhD, ${ }^{b}$ \\ Cincinnati, Ohio, and St Louis, Mo
}

Our laboratory has been investigating fetal bypass for more than a decade because of the possibility that fetal cardiac interventions may prevent the development of certain congenital heart lesions. In many of our studies and much of the past experimental work, the placenta has served as the sole source of oxygenation for fetal bypass because of the long-standing prevailing hypothesis that high oxygen tension $\left(\mathrm{Po}_{2}\right)$ causes an increase in placental vascular resistance. ${ }^{1,2}$ However, the effect of prime $\mathrm{Po}_{2}$ concentration on placental vascular resistance and umbilical blood flow in the setting of fetal bypass has not been reported in the literature. Knowledge of the effect of prime $\mathrm{PO}_{2}$ concentration on placental vasculature is required to determine whether unique circuitry is necessary for fetal cardiac bypass. We have found that elevated $\mathrm{Po}_{2}$ concentration of the prime does not have an acute or long-term deleterious effect on placental vascular resistance, umbilical blood flow, or fetal metabolism. These findings suggest that manipulation of the prime $\mathrm{Po}_{2}$ to match fetal $\mathrm{Po}_{2}$ concentrations is not necessary and further supports the potential efficacy of using modern clinical tools used in neonatal practice with fetal bypass.

\section{CLINICAL SUMMARY}

All animals received humane care in compliance with the Guide for the Care and Use of Laboratory Animals (National Instititues of Health publication No. 85-23; revised 1996). By using standard fetal bypass methods that others and we have previously described, ${ }^{3,4}$ we examined the effect of prime $\mathrm{Po}_{2}$ on the fetal blood lactate and hemodynamic variables on 9 fetal sheep with a mean gestational age of 116 days (term, $\sim 148$ days). The placenta served as the sole source of oxygen. The prime $\mathrm{PO}_{2}$ was manipulated with nitrogen to create a range of prime $\mathrm{Po}_{2}$ values, ranging from values corresponding to normal fetal to neonatal environment (arterial oxygen

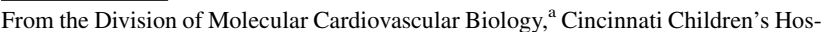
pital Medical Center, Cincinnati, Ohio; and Division of Cardiothoracic Surgery, ${ }^{b}$ Washington University Medical Center, St Louis, Mo.

Disclosures: Authors have nothing to disclose with regard to commercial support.

Received for publication Sept 10, 2013; revisions received Oct 27, 2013; accepted for publication Nov 11, 2013; available ahead of print Dec 27, 2013.

Address for reprints: Pirooz Eghtesady, MD, PhD, Pediatric Cardiothoracic Surgery, Washington University School of Medicine, Campus Box 8234, St Louis, MO 63110 (E-mail: eghtesadyp@wudosis.wustl.edu).

J Thorac Cardiovasc Surg 2014;147:1107-8

$0022-5223 / \$ 36.00$

Copyright (C) 2014 by The American Association for Thoracic Surgery

http://dx.doi.org/10.1016/j.jtcvs.2013.11.023
}

2' on CPB Umbilical Blood Flow vs Prime pO2

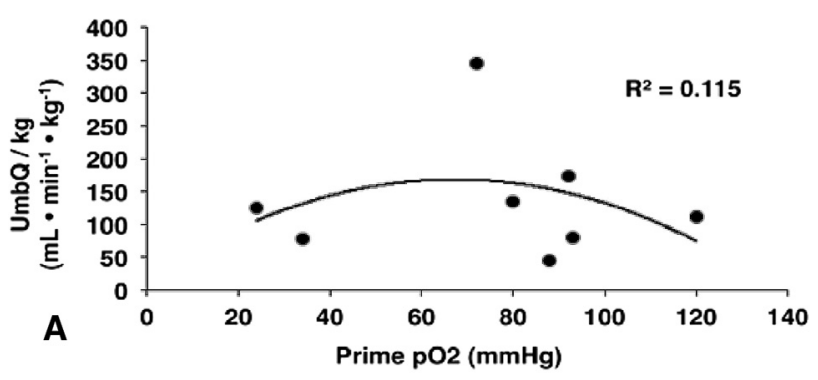

2' on CPB Umbilical Vascular Resistance vs Prime pO2

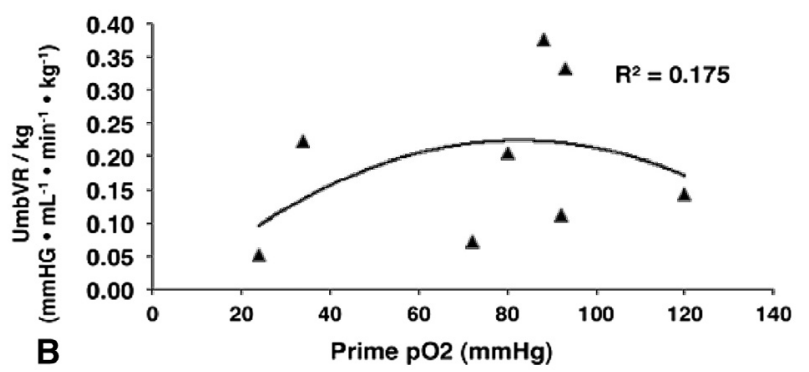

FIGURE 1. There is not a deleterious effect of prime $\mathrm{Po}_{2}$ concentration on umbilical blood flow and umbilical vascular resistance at 2 minutes after initiation of bypass. There was no correlation between umbilical blood flow and prime $\mathrm{Po}_{2}\left(R^{2}=0.115\right)(\mathrm{A})$ or between umbilical vascular resistance and prime $\mathrm{Po}_{2}\left(R^{2}=0.175\right)(\mathrm{B}) . C P B$, Cardiopulmonary bypass; $P_{2}$, oxygen tension.

tension, 20-120 $\mathrm{mm} \mathrm{Hg}$ ). Other prime values remained consistent with previously described values. ${ }^{3}$ All animals underwent 30 minutes of bypass with 90 minutes of off-pump reperfusion. A 4- to 6-mm Doppler flow probe (Transonic Systems, Ithaca, NY) placed on the common umbilical artery measured umbilical blood flow. Placental vascular resistance was calculated as reported previously. ${ }^{4}$ Fetal arterial, prime $\mathrm{Po}_{2}$, and lactate values were measured with an i-STAT clinical analyzer (i-STAT Corp, Windsor, NJ).

We examined the immediate effect of prime $\mathrm{PO}_{2}$ on umbilical blood flow and umbilical vascular resistance at 2 minutes after initiation of bypass (Figure 1). There was no correlation between umbilical blood flow $\left(R^{2}=0.115\right)$ and umbilical vascular resistance $\left(R^{2}=0.175\right)$ according to prime $\mathrm{PO}_{2}$ values. We next evaluated umbilical blood flow, umbilical vascular resistance, and lactate values at the conclusion of 30 minutes of bypass and again found no correlation among umbilical blood flow $\left(R^{2}=0.012\right)$, umbilical vascular resistance $\left(R^{2}=0.101\right)$, and serum lactate 
30 ' on CPB Umbilical Blood Flow vs Prime $\mathrm{pO} 2$

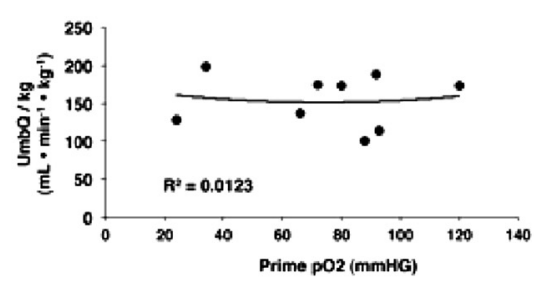

$30^{\prime}$ on CPB Umbilical Vascular Resistance vs Prime pO2

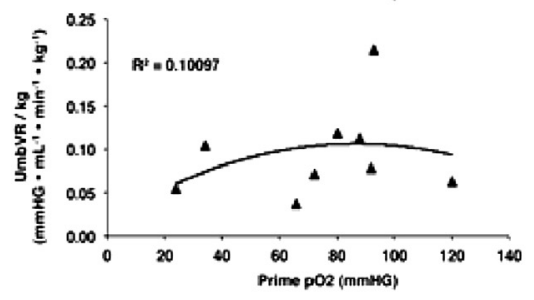

30 ' on CPB Lactate vs Prime pO2

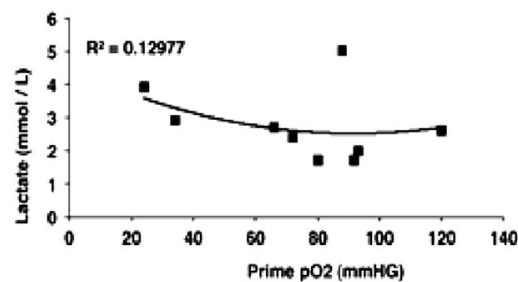

$90^{\prime}$ Post CPB Umbilical Blood Flow vs Prime $\mathrm{pO} 2$

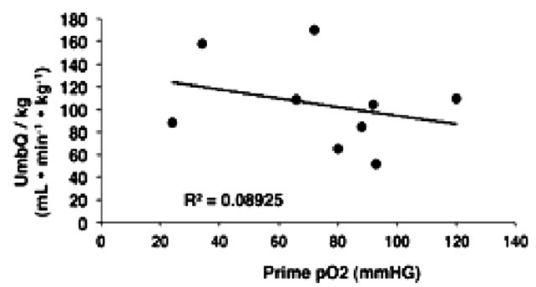

90' Post CPB Umbilical Vascular Resistance vs Prime pO2

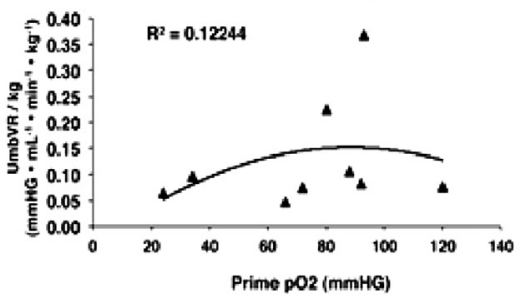

90' Post CPB Lactate vs Prime pO2

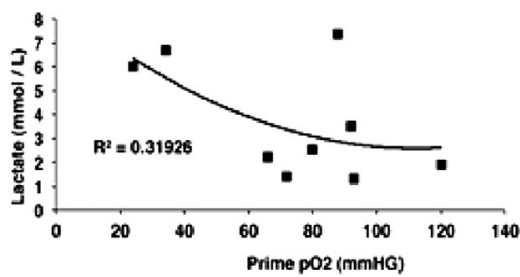

FIGURE 2. There was no correlation between prime $\mathrm{Po}_{2}$ concentration and umbilical blood flow, umbilical vascular resistance, or fetal lactate at 30 minutes after the initiation of cardiopulmonary or at 90 minutes post-bypass. $C P B$, Cardiopulmonary bypass; $\mathrm{Po}_{2}$, oxygen tension.

$\left(R^{2}=0.129\right)$ related to prime oxygen values (Figure 2). Last, we evaluated the long-term effect of prime oxygen on the placental vasculature and fetal lactate at 90 minutes postbypass and found no correlation among umbilical blood flow $\left(R^{2}=0.089\right)$, umbilical vascular resistance $\left(R^{2}=0.122\right)$, and serum lactate $\left(R^{2}=0.319\right)$ related to prime $\mathrm{PO}_{2}$ values (Figure 2), but fetal lactate was trending toward an improved value for the animals that had a higher prime $\mathrm{PO}_{2}$.

\section{DISCUSSION}

Our findings indicated that elevated prime $\mathrm{PO}_{2}$ concentration does not have a deleterious effect on placental vascular resistance, umbilical blood flow, or fetal metabolism. Manipulating the prime oxygen to match fetal oxygen concentration as a therapeutic modality before fetal bypass seems unnecessary, contrary to what was anticipated on the basis of prior obstetrical studies. ${ }^{1,2}$ Furthermore our data suggest that a moderate prime $\mathrm{Po}_{2}(50-80 \mathrm{~mm} \mathrm{Hg})$ may be beneficial. Continued research has shown that fetal bypass with ultra-filtration and the ability to modify $\mathrm{Po}_{2}$, carbon dioxide, $\mathrm{pH}$, and lactate levels can improve fetal hemodynamic parameters during and after bypass. ${ }^{5}$
A minimal circuit cannot ensure that the placenta and other fetal organs receive oxygenated blood during bypass in circumstances in which the placenta itself may be compromised, such as fetal hydrops, which is a real possibility in the clinical setting.

\section{CONCLUSIONS}

These findings suggest that experimental fetal bypass and cardiac surgery may be feasible with standard clinical tools currently used in neonatal practice.

\section{References}

1. Okatani Y, Watanabe K, Wakatsuki A, Tamura S, Sagara Y. Effects of superoxide and peroxynitrite on vascular tension in the human umbilical artery. Acta Obstet Gynecol Scand. 1998;77:883-8.

2. Blanco CE, Martin CB, Rankin J, Landauer M, Phernetton T. Changes in fetal organ flow during intrauterine mechanical ventilation with or without oxygen. J Dev Physiol. 1988;10:53-62.

3. Baker RS, Lam CT, Heeb EA, Hilshorst JL, Ferguson R, Lombardi J, et al. A simple solution is "prime" for fetal cardiopulmonary bypass. ASAIO J. 2007:53:710-5.

4. Baker RS, Lam CT, Heeb EA, Eghtesady P. Dynamic fluid shifts induced by fetal bypass. J Thorac Cardiovasc Surg. 2009;137:714-22.

5. Petrucci O, Baker RS, Lam CT, Reed CA, Duffy JY, Eghtesady P. Fetal right ventricular myocardial function is better preserved by fibrillatory arrest during fetal cardiac bypass. Ann Thorac Surg. 2010;90:1324-31. 